\title{
Secondary stroke prevention services in Canada: a cross-sectional survey and geospatial analysis of resources, capacity and geographic access
}

\author{
Lauren Jewett BSc MGIS, Adil Harroud MD, Michael D. Hill MD MSc, Robert Côté MD, \\ Theodore Wein MD, Eric E. Smith MD MPH, Gord Gubitz MD, Andrew M. Demchuk MD, \\ Demetrios J. Sahlas MD MSc, David J. Gladstone MD PhD, M. Patrice Lindsay RN PhD
}

\section{Abstract}

Background: Rapid assessment and management of transient ischemic attacks and nondisabling strokes by specialized stroke prevention services reduces the risk of recurrent stroke and improves outcomes. In Canada, with its vast geography and with $16.8 \%$ of the population living in rural areas, access to these services is challenging, and considerable variation in access to care exists. The purpose of this multiphase study was to identify sites across Canada providing stroke prevention services, evaluate resource capacity and determine geographic access for Canadians.

Methods: We developed a Stroke Prevention Services Resource Inventory that contained 22 questions on the organization and delivery of stroke prevention services and quality monitoring. The inventory ran from November 2015 to January 2016 and was administered online. We conducted a geospatial analysis to estimate access by drive times. Considerations were made for hours of operation and access within and across provincial borders.

Results: A total of 123 stroke prevention sites were identified, of which 119 (96.7\%) completed the inventory. Most (95) are designated stroke prevention or rapid assessment clinics. Of the 119 sites, 68 operate full time, and 39 operate less than 2.5 days per week. A total of $87.3 \%$ of the Canadian population has access to a stroke prevention service within a 1-hour drive; however, only $69.2 \%$ has access to a service that operates 5-7 days a week. Allowing provincial border crossing improves access ( $<$-h drive) for those who are beyond a 6-hour drive within their home province (3.4\%).

Interpretation: Most Canadians have reasonable geographic access to stroke prevention services. Allowing patients to cross borders improves the existing access for many, particularly some remote communities along the Ontario-Quebec and British Columbia-Alberta borders.

troke and transient ischemic attack (TIA) result in about 62000 hospital visits in Canada annually. ${ }^{1}$ The risk of recurrent stroke after a first ischemic stroke is around $20 \%$ at 5 years. ${ }^{2}$ With TIA, the early risk of subsequent stroke is similar, with reported rates within 90 days of $9 \%-17 \% .^{3}$ This risk is "frontloaded" in the first 48 hours. Roughly $23 \%$ of strokes are preceded by a TIA. ${ }^{4}$ Secondary stroke prevention is crucial to reduce the burden on the health care system and costs, and to improve patient outcomes. ${ }^{5}$ Hospital admission following TIA or minor stroke is associated with expedited initiation of secondary stroke prevention and improved outcomes. ${ }^{6}$ However, current practice in most of Canada is not to admit patients with TIA and even some with mild, nondisabling stroke to inpatient care. ${ }^{7}$ Kapral and colleagues ${ }^{8}$ reported that less than half of patients with TIA and minor stroke are admitted, which emphasizes the importance of improving outpatient prevention services.
Stroke prevention services are specialized interdisciplinary clinics that perform detailed assessments following an index TIA or stroke, and provide timely diagnostic testing and interventions to mitigate the risk of recurrent stroke and functional disability. Evidence-based stroke prevention interventions that decrease the risk of subsequent stroke include blood pressure control, treatment with antiplatelet medication, anticoagulation for atrial fibrillation, carotid

Competing interests: See the end of the article.

This study was presented in part at the 2016 Canadian Stroke Congress, Sept. 15-17, 2016, Québec, Que.

This article has been peer reviewed.

Correspondence to: Patrice Lindsay, patrice.lindsay@ heartandstroke.ca CMAJ Open 2018. DOI:10.9778/cmajo.20170130 
revascularization, lipid-lowering therapy and lifestyle changes. ${ }^{9}$ Observational data suggest that postevent referral to organized outpatient stroke prevention services reduces mortality at 1 year. .,10 $^{2}$

The Canadian Stroke Best Practice Recommendations ${ }^{11}$ facilitate uptake and implementation of evidence-based processes and interventions aimed at decreasing stroke recurrence, but the extent to which they are implemented in routine practice is unknown. ${ }^{12}$ Beyond the capacity of each prevention service, it is essential to ensure the geographic distribution of these services in order to provide accessible care for Canadians, $16.8 \%$ of whom live in rural and remote regions. ${ }^{13}$ Population increases have brought towns previously classified as rural into urban status, even though they are geographically far from major urban centres, where centralized and specialized care is more likely. The growth of these rural towns, coupled with a quickly aging population, necessitates more advanced and quantitative evaluation of delivery of health care services, with a patient lens of accessibility.

We sought to create a comprehensive portrait of secondary stroke prevention services in Canada including geographic distribution, population coverage, access to experts, diagnostic services and evidence-based treatments through a resource inventory and geospatial mapping analysis of all known stroke prevention services. This study builds on previous work evaluating geographic access to advanced emergency stroke services in Canada and access to thrombolysis and endovascular thrombectomy. ${ }^{14}$ Moreover, this study examines the capacity for care at each stroke prevention service surveyed and considers the impact on geographic access to these services should patients be limited to care in their home province and not cross borders to access a closer service. This knowledge will support system planning and resource allocation across Canada.

\section{Methods}

\section{Inventory design}

The Stroke Prevention Services Resource Inventory (available from the authors on request) included 22 binary-choice questions, forced-choice questions and open-ended items on the organization of stroke prevention services, including hours of operation, patient volume, services provided and wait times $(n=10)$; delivery of stroke prevention services, including availability of allied health care professionals, diagnostic resources and follow-up practices $(n=8)$; and quality monitoring $(n=4)$. We developed items for the inventory using elements contained in the Secondary Prevention of Stroke best practice recommendations module ${ }^{11}$ and literature reviews, then validated through a 4-round modified Delphi process. ${ }^{15}$ Questions were included that achieved greater that $80 \%$ consensus on the final round. Participating services were identified through collaboration with provincial Heart and Stroke leaders, ministries of health and Canadian Stroke Consortium members, and each inventory was completed by local prevention service staff members, most often a manager or prevention nurse in consultation with his or her team. No stroke prevention services were identified in the Yukon Territory, Northwest Territories or Nunavut. The inventory ran from November 2015 to January 2016 and was administered online through SurveyMonkey (www.surveymonkey.com). There was no financial incentive for participation. Follow-up contact was made to clarify or complete information.

\section{Geospatial analysis}

We geocoded the location of each stroke prevention service in ArcMap 10.3 (Environmental Systems Research Institute Canada) using the 6-digit postal code of the site and reference postal code locations. ${ }^{16}$ Each site was manually verified and its location edited by comparing against Google Maps (maps. google.ca). We attributed associated inventory data, including name, location and hours of operation, to each stroke prevention site. Lloydminster Hospital was considered part of both Alberta and Saskatchewan and was counted in both provincial counts; however it was counted only once for the total number.

To estimate geographic access to the stroke prevention services, we calculated drive time and distance to each site for the Canadian population. We modelled the road network using ArcMap Network Analyst (default settings) and a roads data set, including highways and major and local roads with posted speed limits and restrictions. ${ }^{17}$ To determine the location of origin for travel, we used the 2016 Canadian census to identify the geographic locations of neighbourhoods and population counts by dissemination area. ${ }^{18}$ Given that the dissemination area region size is based on population density, rural and remote areas can be very large, and the exact geographic centre likely does not represent where most of the population lives, containing farmland, water or mountains. Postal code locations (local delivery units) are used for mail delivery, so clusters of points that represent these areas, within each dissemination area, are likely to be where most people live. Therefore, we calculated a postal-code-weighted geographic mean centre to produce a single point of origin for each dissemination area. This point allowed for calculation of travel time to the closest site along the road network, obeying all posted signs and speed limits, without any traffic or weather delay.

We stratified the population data points by the associated calculated drive times with the following categories: less than 1 hour, 1-2 hours, 2-3 hours, 3-4 hours, 4-5 hours, 5-6 hours and more than 6 hours. Analysis was completed with and without provincial border restrictions. The territories are not included in the resulting information and summary tables. The population in the territories is still included as part of the denominator value that represents the entire population of Canada and is considered as part of the population without access to any stroke prevention services (> 6-h drive).

\section{Prevention service hours of operation}

We categorized each service by number of half-days per week that prevention services are available. This stratification is important to geographic access because patients who are closest to a service that is not frequently open do not have the 
same time-sensitive access as those who live closest to a frequently open location. Hours of operation were grouped into 4 categories: type A (services available for 1-2 half-days per week), type B (services available 3-5 half-days), type C (services available 6-8 half-days) and type D (services available 9-14 half-days). Type A and B services were considered infrequently open, and types $\mathrm{C}$ and $\mathrm{D}$ were considered frequently open. To determine the impact of access to infrequently open sites, we evaluated the additional driving burden if communities are forced to bypass a closer type A or B site to go to the next closest type $\mathrm{C}$ or $\mathrm{D}$ site.

\section{Analysis}

We conducted descriptive analysis of the inventory data. The data were stratified as appropriate, including urban or rural ${ }^{13}$ and provincial.

\section{Results}

Of the 123 stroke prevention sites identified, 119 (96.7\%) completed the Stroke Prevention Services Resource Inventory. Data were complete for all 119 sites. The 4 nonrespondent sites were in Quebec $(n=2)$ and Newfoundland and

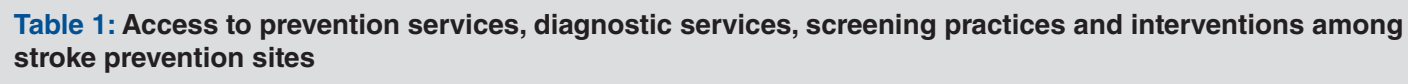

\begin{tabular}{|c|c|c|c|c|}
\hline \multirow[b]{2}{*}{ Resource } & \multicolumn{4}{|c|}{ Region; ${ }^{*}$ no. $(\%)$ of sites } \\
\hline & $\begin{array}{l}\text { Canada } \\
n=119\end{array}$ & $\begin{array}{l}\text { Western } \\
\text { region } \\
n=34\end{array}$ & $\begin{array}{l}\text { Central } \\
\text { region } \\
n=68\end{array}$ & $\begin{array}{l}\text { Eastern } \\
\text { region } \\
n=17\end{array}$ \\
\hline Designated stroke prevention service & $95(80)$ & $29(85)$ & $55(81)$ & $11(65)$ \\
\hline $\begin{array}{l}\text { Capacity to provide assessment within } 24 \mathrm{~h} \text { for } \\
\text { high-risk patients with TIA or nondisabling stroke } \\
\text { most of the time (> } 50 \% \text { of requests) }\end{array}$ & $48(40)$ & $17(50)$ & $26(38)$ & $5(29)$ \\
\hline Stroke prevention services within urban centre & $82(69)$ & $20(59)$ & $53(78)$ & $9(53)$ \\
\hline Stroke prevention services within rural area & $37(31)$ & $14(41)$ & $16(24)$ & $7(41)$ \\
\hline \multicolumn{5}{|l|}{ Neuroimaging } \\
\hline Same-day computed tomography & $68(57)$ & $22(65)$ & $39(57)$ & $7(41)$ \\
\hline Magnetic resonance imaging within $48 \mathrm{~h}$ & $28(24)$ & $7(20)$ & $17(25)$ & $4(24)$ \\
\hline No access to any neuroimaging & $12(10)$ & $4(12)$ & $5(7)$ & $3(18)$ \\
\hline \multicolumn{5}{|l|}{ Vascular imaging } \\
\hline Same-day computed tomography angiography & $44(37)$ & $15(44)$ & $24(35)$ & $5(29)$ \\
\hline Same-day carotid Doppler ultrasonography & $42(35)$ & $14(41)$ & $23(34)$ & $5(29)$ \\
\hline \multicolumn{5}{|l|}{ Cardiac investigations } \\
\hline Holter monitoring within $7 \mathrm{~d}$ & $82(69)$ & $23(68)$ & $47(69)$ & $12(70)$ \\
\hline Any access to prolonged cardiac monitoring & $86(72)$ & $20(59)$ & $58(85)$ & $8(47)$ \\
\hline $\begin{array}{l}\text { Any access to transthoracic/transesophageal } \\
\text { echography }\end{array}$ & $95(80)$ & $28(82)$ & $55(81)$ & $12(70)$ \\
\hline \multicolumn{5}{|l|}{ Intervention } \\
\hline Carotid endarterectomy within $14 \mathrm{~d}$ & $61(51)$ & $16(47)$ & $38(56)$ & $7(41)$ \\
\hline No access to carotid endarterectomy & $13(11)$ & $5(15)$ & $5(7)$ & $3(18)$ \\
\hline \multicolumn{5}{|l|}{ Screening practices } \\
\hline $\begin{array}{l}\text { Risk of recurrent stroke in atrial fibrillation } \\
\text { (e.g., as assessed with CHADS2) }\end{array}$ & $99(83)$ & $30(88)$ & $56(82)$ & $13(76)$ \\
\hline National Institutes of Health Stroke Scale & $38(32)$ & $15(44)$ & $22(32)$ & $1(6)$ \\
\hline Canadian Neurological Scale & $34(29)$ & $8(24)$ & $17(25)$ & $9(53)$ \\
\hline Cognitive impairment routinely screened & $70(59)$ & $20(59)$ & $45(66)$ & $5(29)$ \\
\hline Depression routinely screened & $65(55)$ & $17(50)$ & $38(56)$ & $10(59)$ \\
\hline $\begin{array}{l}\text { Functional ability screened with Modified } \\
\text { Rankin Scale }\end{array}$ & $31(26)$ & $9(26)$ & $19(28)$ & $3(18)$ \\
\hline $\begin{array}{l}\text { Note: TIA = transient ischemic attack. } \\
\text { "Western region includes British Columbia, Alberta and Sask } \\
\text { includes Nova Scotia, New Brunswick, Prince Edward Island }\end{array}$ & oundland & 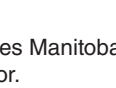 & & ern region \\
\hline
\end{tabular}


Labrador $(n=2)$ and were within a general risk factor clinic or hypertension clinic, not specific to stroke alone.

\section{Stroke prevention services}

There were $95(80.5 \%)$ dedicated stroke prevention services, 29 of which provided urgent assessment of TIA or minor stroke. Other services (30 [25.2\%]) were provided by internal medicine, general/urgent neurology, cardiovascular and vascular clinics. Most services (93 [78.2\%]) were part of an acute care hospital, and $82(68.9 \%)$ were urban. Eighty services (67.2\%) functioned for 3 days or more per week within an outpatient clinic setting. Referral sources included emergency departments (103 [86.6\%]), family physicians (102 [85.7\%]), acute inpatient units (73 [61.3\%]), other specialty clinics $(54[45.4 \%])$, rehabilitation centres (45 [37.8\%]) and other ambulatory clinics (30 [25.2\%]). In 67 locations $(56.3 \%)$, patients were seen for a first visit, then followed for an additional 1 or 2 visits before being discharged to primary care; $23(19.3 \%)$ assessed patients only once; and $20(16.8 \%)$ followed patients in the long term; the remaining 9 locations $(7.6 \%)$ did not provide a description.

Professional staffing varied, and only 52 sites (43.7\%) reported access to a stroke neurologist. Other physicians involved in stroke prevention care were general neurologists $(45[37.8 \%])$, internists (34 [28.6\%]), family physicians $(18[15.1 \%])$ and physiatrists $(11[9.2 \%])$. One-third (43 [36.1\%]) of services reported having a stroke clinical nurse specialist, and $71(59.7 \%)$, a staff nurse. Table 1 shows the access to diagnostic services, screening practices and interventions.

\section{Geospatial analysis}

The geospatial analysis showed that $87.3 \%$ of the Canadian population (range $44.9 \%$ [Newfoundland and Labrador] to $97.0 \%$ [Ontario]) live within 1-hour drive to the nearest stroke prevention services, and the average drive time is deviation 38.6) minutes, ignoring provincial boundaries (Figure 1, Table 2, Table 3). Less than $80 \%$ of the population has access within a 1-hour drive in each of the following

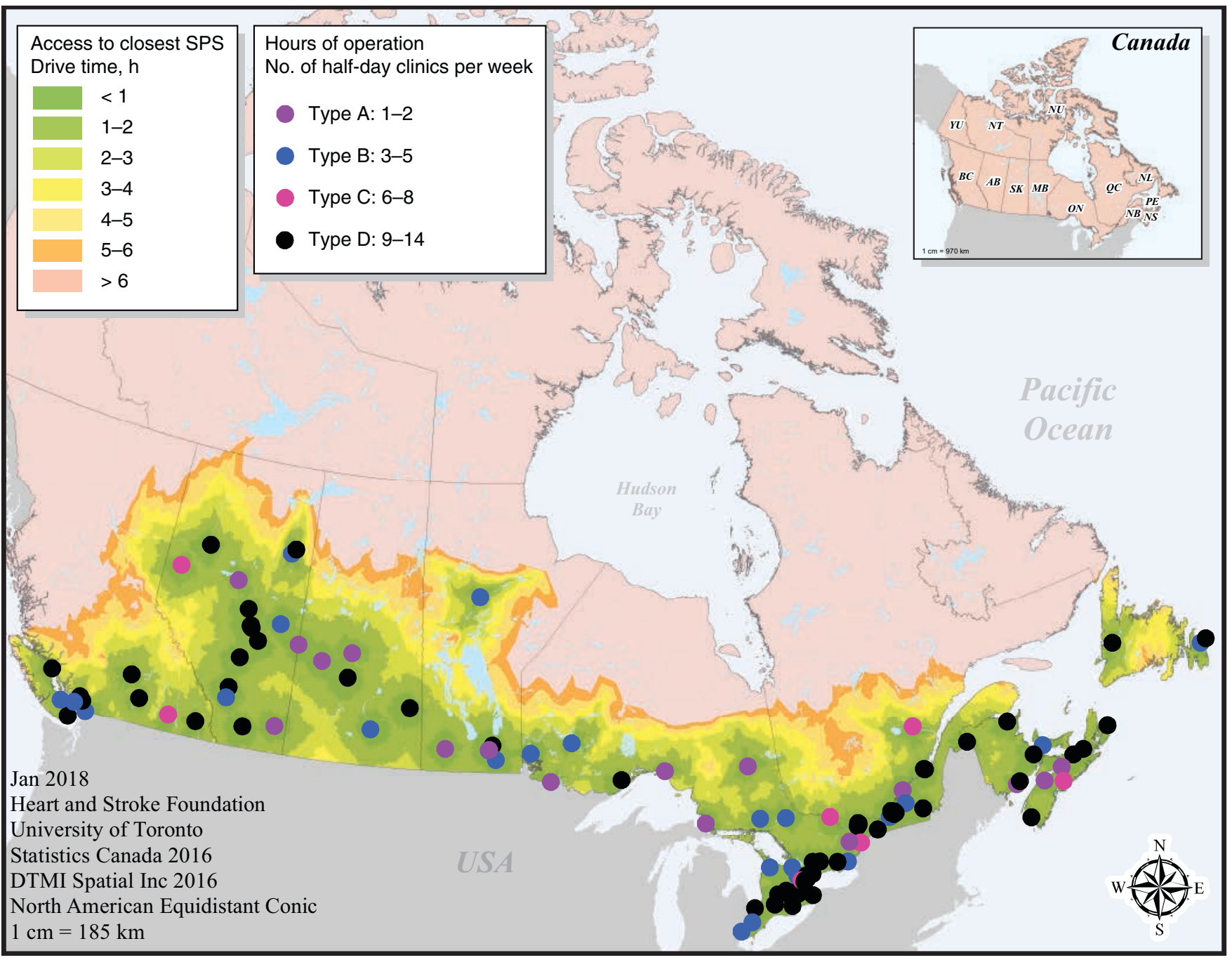

Figure 1: Access to stroke prevention sites across Canada, allowing patients to cross provincial borders to seek care. Note: SPS $=$ stroke prevention site. 


\begin{tabular}{|c|c|c|c|c|c|c|c|c|}
\hline \multirow[b]{2}{*}{ Province/territory $†$} & \multicolumn{8}{|c|}{ Drive time; $\%$ of population with access to closest stroke prevention site } \\
\hline & Intraprovince & Interprovince & Intraprovince & Interprovince & Intraprovince & Interprovince & Intraprovince & Interprovince \\
\hline $\begin{array}{l}\text { British Columbia } \\
(n=12)\end{array}$ & 79.3 & 79.3 & 5.8 & 6.2 & 5.5 & 6.7 & 9.3 & 7.7 \\
\hline Saskatchewan $(n=6) \ddagger$ & 63.4 & 63.5 & 22.2 & 24.3 & 13.6 & 11.5 & 0.8 & 0.7 \\
\hline Manitoba $(n=6)$ & 78.3 & 78.7 & 12.1 & 13.6 & 6.9 & 5.0 & 2.7 & 2.7 \\
\hline Ontario $(n=48)$ & 97.0 & 97.0 & 2.3 & 2.3 & 0.3 & 0.3 & 0.4 & 0.4 \\
\hline Quebec $(n=15)$ & 91.8 & 91.9 & 4.9 & 5.1 & 2.4 & 2.4 & 1.0 & 0.5 \\
\hline $\begin{array}{l}\text { Newfoundland and } \\
\text { Labrador }(n=3)\end{array}$ & 44.9 & 44.9 & 12.6 & 12.6 & 33.1 & 33.1 & 9.4 & 9.4 \\
\hline $\begin{array}{l}\text { Yukon, Northwest } \\
\text { Territories, Nunavut } \\
(n=0)\end{array}$ & 0.0 & 0.0 & 0.0 & 0.0 & 0.0 & 0.0 & 100.0 & 100.0 \\
\hline Canada $(n=119)$ & 87.2 & 87.3 & 6.3 & 6.5 & 3.1 & 3.2 & 3.4 & 3.1 \\
\hline
\end{tabular}

5 provinces: British Columbia, Saskatchewan, Manitoba, New Brunswick and Newfoundland and Labrador. A total of 3.1\% of Canadians do not have any access within a 6-hour drive (Table 2).

The most notable differences for drive times related to crossing provincial borders were found among the rural populations living in British Columbia and Quebec. Figure 2 illustrates the increased access to stroke prevention services for Quebec communities along the Ontario-Quebec border when border crossing is permitted to allow Quebec patients to access closer services in Ontario. A similar trend takes place for those crossing from the northern British Columbia border into closer services in northern Alberta.

When hours of operation were considered, type D services (full-time operation) were closest for $69.2 \%$ of the Canadian population (Table 4). The average drive time to bypass closer type $\mathrm{A}$ or $\mathrm{B}$ sites to access type $\mathrm{C}$ or $\mathrm{D}$ services would be 57.9 minutes (range $0.7 \mathrm{~min}$ [New Brunswick] to $98.8 \mathrm{~min}$ [Ontario]). This difference in New Brunswick is because a type D service is located slightly past the type A service. These variations were affected by the uneven geographic distribution of services with different hours of operation within and across provinces.

\section{Interpretation}

Most Canadians (96.9\%) have access to stroke prevention services within a 6-hour drive of their home residence, or a driv- ing distance of about $600 \mathrm{~km}$. When considering hours of service operation, $91.1 \%$ of Canadians have access within a 6-hour drive to services operating more than 2.5 days per

\begin{tabular}{|c|c|c|}
\hline \multirow[b]{2}{*}{ Province* } & \multicolumn{2}{|c|}{ Mean $\pm \mathrm{SD}, \min$} \\
\hline & $\begin{array}{l}\text { Intraprovince } \\
\text { access }\end{array}$ & $\begin{array}{c}\text { Interprovince } \\
\text { access }\end{array}$ \\
\hline British Columbia $(n=12)$ & $33.1 \pm 61.4$ & $33.0 \pm 61.0$ \\
\hline Alberta $(n=17)$ & $24.0 \pm 30.6$ & $24.0 \pm 31.0$ \\
\hline Saskatchewan $(n=6)$ & $55.8 \pm 58.6$ & $52.2 \pm 52.1$ \\
\hline Manitoba $(n=6)$ & $35.0 \pm 52.1$ & $32.9 \pm 61.0$ \\
\hline Ontario $(n=48)$ & $15.5 \pm 17.3$ & $5.4 \pm 17.3$ \\
\hline Quebec $(n=15)$ & $25.4 \pm 46.2$ & $22.7 \pm 32.2$ \\
\hline New Brunswick $(n=5)$ & $39.6 \pm 30.1$ & $39.6 \pm 30.1$ \\
\hline Nova Scotia $(n=7)$ & $24.0 \pm 23.1$ & $23.5 \pm 22.4$ \\
\hline Prince Edward Island $(n=1)$ & $35.2 \pm 20.1$ & $35.2 \pm 20.1$ \\
\hline $\begin{array}{l}\text { Newfoundland and Labrador } \\
(n=3)\end{array}$ & $91.2 \pm 88.3$ & $91.3 \pm 88.3$ \\
\hline Canada $(n=119)$ & $25.8 \pm 42.5$ & $24.9 \pm 38.6$ \\
\hline
\end{tabular}




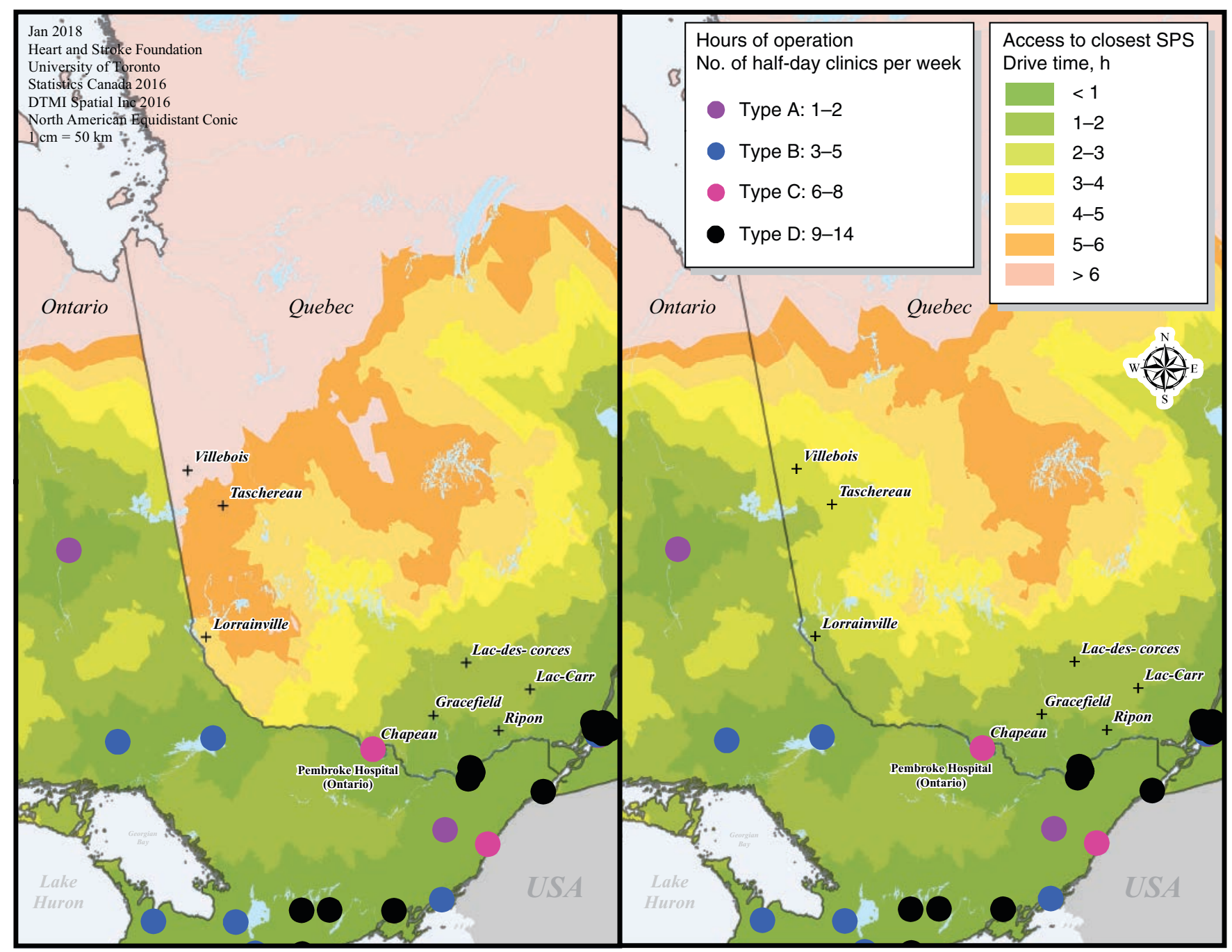

Figure 2: Drive time to closest secondary stroke prevention site for Quebec patients when Ontario-Quebec border crossing is not permitted (left) and when border crossing is permitted (right). Note: SPS = stroke prevention site.

week. Allowing patients to cross provincial borders to seek stroke prevention services reduces the travel time for rural patients and allows access for others who are beyond a 6-hour drive within their home province. Issues related to border crossing mostly affect those along the British ColumbiaAlberta and Ontario-Quebec borders, where large cities can be found on 1 side of the border housing more advanced medical facilities than rural towns across the border. To facilitate increased access across borders, issues of insurance coverage, reimbursement for services and provincial health agreements need to be addressed. There are no stroke prevention services identified in the Yukon Territory, Northwest Territories or Nunavut; communities in these jurisdictions rely on primary care services within their home regions or referrals to provinces.

Some stroke prevention sites are open for more hours than others, usually dependant on the patient volumes expected and human resources available at the site. We estimated an average additional travel time of less than 1 hour for those to bypass their closer, infrequently open site to access a more frequently open site. Without clinical data, it is challenging to speculate how often these bypassing routes are taken by patients; however, this should now inform planning and evaluation of the overall effectiveness of the network of services.

We found that fewer than half of stroke prevention sites have access to a stroke neurologist. Many sites did not meet best-practice recommendation target times for assessment and management. The reasons may be related to access to expert human resources, diagnostic equipment and certain interventions. For example, a recent report highlighted underuse of appropriate cardiac rhythm monitoring in patients with stroke, with $31 \%$ receiving 24 hours of monitoring and less than $1 \%$ receiving prolonged monitoring. ${ }^{19}$ Ambulatory Holter monitoring was available at $95 \%$ of reporting services, whereas access to prolonged atrial fibrillation monitoring within 7 days of being seen by the prevention service was available at only $35 \%$ of services. Therefore, our study shows that, while lack of access likely plays a role in the low proportion of sites offering prolonged monitor- 
Table 4: Proportion of population closest to a stroke prevention site, by hours of operation

\begin{tabular}{|c|c|c|c|c|c|c|c|c|}
\hline Province & $\begin{array}{l}\text { Population (\%) } \\
(2016)^{18}\end{array}$ & \multicolumn{4}{|c|}{$\begin{array}{c}\text { Hours of operation type } \\
\% \text { of population }\end{array}$} & \multicolumn{3}{|c|}{$\begin{array}{l}\text { Drive time to closest type } C \text { or } D \text { facility for those } \\
\text { with closest site being type } A \text { or } B \\
\text { mean } \pm S D \text {, min }\end{array}$} \\
\hline British Columbia & 4756433 (13.5) & 0.0 & 31.1 & 14.1 & 50.2 & $15.1 \pm 17.3$ & $33.7 \pm 26.4$ & $18.8 \pm 18.7$ \\
\hline Manitoba & 1299134 (3.7) & 35.9 & 34.2 & 0.0 & 26.7 & $31.7 \pm 44.4$ & $68.6 \pm 103.8$ & $37.0 \pm 83.8$ \\
\hline Ontario & 13470549 (38.2) & 2.3 & 15.6 & 4.0 & 77.8 & $26.7 \pm 28.6$ & $125.3 \pm 108.7$ & $98.8 \pm 104.2$ \\
\hline Quebec & 7810575 (22.1) & 9.0 & 8.0 & 3.6 & 78.7 & $39.1 \pm 61.6$ & $80.3 \pm 99.5$ & $41.3 \pm 53.4$ \\
\hline New Brunswick & $747101(2.1)$ & 12.7 & 0.0 & 0.0 & 87.3 & $20.3 \pm 12.9$ & $21.2 \pm 13.4$ & $0.7 \pm 2.1$ \\
\hline $\begin{array}{l}\text { Newfoundland and } \\
\text { Labrador }\end{array}$ & $545301(1.5)$ & 0.0 & 15.6 & 0.0 & 75.0 & $10.3 \pm 6.1$ & $11.3 \pm 6.2$ & $1.0 \pm 1.0$ \\
\hline Canada & $35284108(100.0)$ & 6.4 & 16.2 & 5.7 & 69.2 & $31.4 \pm 41.9$ & $89.1 \pm 92.0$ & $57.9 \pm 77.3$ \\
\hline
\end{tabular}

ing, access is unlikely the limiting factor for Holter monitoring.

The benefits of carotid endarterectomy are maximized when it is performed within 2 weeks of the index cerebrovascular event. However, with only $51 \%$ of services reporting access to this procedure within this target time, this well-recognized evidence-to-practice gap persists. ${ }^{20}$ Importantly, $11 \%$ of services reported not having any access to carotid endarterectomy. In line with these findings, a study of patients with TIA or minor stroke presenting to the emergency department in Ontario between 2008 and 2011 showed that hospital admission is associated with more expeditious investigations and therapy initiation, even when compared to referral to a stroke prevention service. ${ }^{6}$ However, bed capacity is limited in most hospitals in Canada, and patients with TIA or mild, nondisabling stroke are generally not admitted. Improved access to diagnostics and therapeutic measures is crucial to improve the performance of outpatient management regarding these patients, who are at high risk for early stroke recurrence.

\section{Limitations}

This study is based on a model of access to services and therefore is subject to limitations. First, the inventory was selfreported and was not evaluated objectively by the project team. A validation of the findings was undertaken with provincial stroke leaders to improve data quality. The accuracy of the geospatial model is limited by the accuracy of the data used to create it. We validated the drive times generated by the road network against Google Maps drive times and found them to be consistent. Considering that the dissemination areas in rural regions span a much larger geographic area than those in urban regions, the variance in drive times between exact households and the weighted centre origin used in analysis is likely greater in rural areas. Therefore, those who experience vastly different drive times from what is estimated are likely those who do not live in even small remote towns but, instead, live in isolated settings such as farmland.

\section{Conclusion}

The network of stroke prevention services in Canada is extensive and has the potential to provide access to most Canadian communities. This research is a step forward in understanding the geographic and nongeographic disparities in access to preventive stroke care. Information on how border crossing affects access should be noted, considering that the standard practice of budgeting and allocating resources is for those who live in a province and not necessarily for those who seek care in that province. This model can be expanded to include more characteristics of services available, integrated with knowledge of specific communities, such as vascular risk profiles, socioeconomic status, ethnic make-up and health behaviours. Understanding the geodemographic characteristics of regions with and without access to stroke prevention services will inform health care system planning, resource allocation, funding and public health initiatives. It will also help target resource priorities to improve stroke prevention, education and services that can reduce the burden of stroke on families, communities and the Canadian health care system. 


\section{References}

1. Coutts SB, Wein TH, Lindsay MP, et al. Canadian Stroke Best Practice Recommendations: secondary prevention of stroke guidelines, update 2014. Int 7 Stroke 2015;10:282-91.

2. Dhamoon MS, Sciacca RR, Rundek T, et al. Recurrent stroke and cardiac risks after first ischemic stroke The Northern Manhattan Study. Neurology 2006;66: 641-6.

3. Wu CM, McLaughlin K, Lorenzetti DL, et al. Early risk of stroke after transient ischemic attack: a systematic review and meta-analysis. Arch Intern Med 2007;167:2417-22.

4. Rothwell PM, Warlow CP. Timing of TIAs preceding stroke: time window for prevention is very short. Neurology 2005;64:817-20.

5. Krueger H, Lindsay $\mathrm{P}$, Cote $\mathrm{R}$, et al. Cost avoidance associated with optimal stroke care in Canada. Stroke 2012;43:2198-206.

6. Kapral MK, Hall R, Fang J, et al. Association between hospitalization and care after transient ischemic attack or minor stroke. Neurology 2016;86:1582-9.

7. Lindsay P, Lawrence S. Access to stroke care: the critical first bours. Heart and Stroke Foundation annual stroke report. Ottawa: Heart and Stroke Foundation; 2015. Available: www.strokebestpractices.ca/wp-content/uploads/2015/06/ HSF-2015-Stroke-Report_EN-FINAL1.pdf (accessed 2017 Aug. 24).

8. Kapral MK, Hall R, Fang J, et al. Predictors of hospitalization in patients with transient ischemic attack or minor ischemic stroke. Can 7 Neurol Sci 2016;43: 523-8.

9. Hankey GJ. Secondary stroke prevention. Lancet Neurol 2014;13:178-94.

10. Webster F, Saposnik G, Kapral MK, et al. Organized outpatient care. Stroke 2011;42:3176-82.

11. Wein T, Lindsay MP, Côté R, et al.; Heart and Stroke Foundation Canadian Stroke Best Practice Committees. Canadian Stroke Best Practice Recommendations: secondary prevention of stroke, sixth edition practice guidelines, update 2017. Int 7 Stroke 2017;Nov 24 [Epub ahead of print]. doi:10.1177/ 1747493017743062.

12. Brazzelli M, Shuler K, Quayyum Z, et al. Clinical and imaging services for TIA and minor stroke: results of two surveys of practice across the UK. BM7 Open 2013;3:e003359.

13. Census of Canada population by urban and rural. Ottawa: Statistics Canada; 2016.

14. Eswaradass PV, Swartz RH, Rosen J, et al. Access to hyperacute stroke services across Canadian provinces: a geospatial analysis. CMAf̈ Open 2017;5:E454-9.

15. Custer RL, Scarcella JA, Stewart BR. The modified Delphi technique - a rotational modification. 7 Career Tech Educ 1999;15. doi:http://dx.doi.org/ 10.21061/jcte.v15i2.702.

16. Postal Code Suite [online database]. Markham (ON): DMTI Spatial; 2016.

17. CanMap Route Logistics [online database]. Markham (ON): DMTI Spatial; 2016.

18. Census of Canada Population Count by Dissemination Area [online database]. Ottawa: Statistics Canada; 2016.

19. Edwards JD, Kapral MK, Fang J, et al. Underutilization of ambulatory ECG monitoring after stroke and transient ischemic attack. Stroke 2016;47:1982-9.

20. Gladstone DJ, Oh J, Fang J, et al. Urgency of carotid endarterectomy for secondary stroke prevention. Stroke 2009;40:2776-82.

Competing interests: Michael Hill is funded by the Heart and Stroke Foundation Alberta and the Hotchkiss Brain Institute Professorship in
Stroke Research. Robert Côté is on the speaker bureau for Pfizer and Bristol-Myers Squibb. Theodore Wein is a researcher, speaker and consultant for Boehringer Ingelheim, Bayer, Allergan and Servier. Gord Gubitz is an advisory board member for Bayer. David Gladstone is supported by a Mid-Career Award from the Heart and Stroke Foundation of Canada and has received fees from Bayer, Boehringer Ingelheim, BristolMyers Squibb and Pfizer for lectures or for being on an advisory board. No other competing interests were declared.

Affiliations: Department of Geography and Planning (Jewett), University of Toronto, Toronto, Ont.; Department of Neurology and Neurosurgery (Harroud, Côté, Wein) and Department of Medicine (Harroud, Cote, Wein), McGill University, Montréal, Que.; Calgary Stroke Program (Hill, Smith, Demchuk), Hotchkiss Brain Institute, Cumming School of Medicine, University of Calgary, Calgary, Alta; Queen Elizabeth II Health Sciences Centre (Gubitz), Dalhousie University, Halifax, NS; Division of Neurology (Sahlas), Department of Medicine, McMaster University, Hamilton, Ont.; Sunnybrook Health Sciences Centre (Gladstone) and Hurvitz Brain Sciences Research Program (Gladstone), Sunnybrook Research Institute, Department of Medicine, University of Toronto; Heart and Stroke Foundation of Canada (Lindsay), Toronto, Ont.

Contributors: Patrice Lindsay is senior author. She conceived the study, coordinated the analysis and contributed to the interpretation of the data. Adil Harroud, Michael Hill, Robert Côté, Theodore Wein, Eric Smith, Gord Gubitz, Andrew Demchuk, Demetrios Sahlas and David Gladstone contributed to the development of the Stroke Prevention Services Resource Inventory and the interpretation of the data. Lauren Jewett conducted the geospatial analysis. All of the authors contributed to the study design, data analysis and drafting of the manuscript, critically revised the manuscript for important intellectual content, gave final approval of the version to be published and agreed to be accountable for all aspects of the work.

Acknowledgements: The authors acknowledge and thank the staff and university students, including Jennifer Wells and Matthew Lindsay, who entered inventories into the database and followed up with respondents to verify information. They thank Jiming Fang for organizing the output and Jamey Rosen for his consultation on the geospatial analysis. The Canadian Stroke Best Practices and Stroke Quality Advisory Committees provided review and input into the inventory content and interpretation of findings.

Funding: This research was funded by the Heart and Stroke Foundation of Canada.

Supplemental information: For reviewer comments and the original submission of this manuscript, please see www.cmajopen.ca/content/6/1/ E95/suppl/DC1. 